\title{
Interdisciplinaridade na arquitetura: A maquete como instrumento articulador no processo de ensino-aprendizagem.
}

\section{Interdisciplinarity in architecture: The physical model as an articulating tool in the teaching-learning process.}

\section{Nicole Ferrer}

Mestre em Arquitetura pelo Illinois Institute Technology, Chicago-EUA.

Docente do curso de Arquitetura e Urbanismo da FACIMED, Cacoal/RO, Brasil

nicferrer.arq@gmail.com

\section{Luíza Reithler}

Especialista em Gestão de Restauro - Centro de Estudos Avançados da Conservação Integrada.

Docente do curso de Arquitetura e Urbanismo da FACIMED, Cacoal/RO, Brasil

luiza.reithler@gmail.com

\section{RESUMO:}

0 desenvolvimento de um repertório projetual próprio no aluno é um dos principais objetivos no Ensino Superior de Arquitetura e Urbanismo. Para tanto, uma das formas mais vantajosas de fornecer essa capacidade de análise é através da utilização da maquete, já que, para o bom desenvolvimento do protótipo, o acadêmico, além de juntar todas as informações necessárias, deve organizá-las de maneira a reproduzi-las na ordem correta. Deste modo, o presente trabalho tem por objetivo levantar uma discussão pedagógica-metodológica através de uma experiência de interdisciplinaridade entre disciplinas de teoria e prática em conjunto com o uso de ferramentas tradicionais de representação do espaço. Através de um laboratório de pesquisa, a maquete física configurou-se como ferramenta essencial na articulação da concepção do espaço, fazendo com que esta sirva como contribuição ao processo de projeto.

Palavras-chave: maquete física; interdisciplinaridade; ensino da arquitetura.

\section{ABSTRACT:}

The development of the student's own architectonical repertoire is one of the main objectives in the higher education of Architecture and Urbanism. Therefore, one of the most advantegeous ways of providing this analytical capability is through the use of the model, since, for the proper development of the prototype, the academic, in addition to gathering all the necessary information, must organize them in a way that reproduces them in the correct order. So, the presente work aims to raise a pedagogical-methodological discussion through an interdisciplinar experience between disciplines of theory and practice together with the use of tradicional space representation tools. Through a research laboratory, the physical model was configured as an essential tool in the articulation of the space design, making it serve as a contribution to the architectural process.

Keywords: physical model; interdisciplinarity; architecture teaching. 


\title{
1. INTRODUÇÃO
}

O século XXI vê surgir uma profunda transformação nos paradigmas pedagógicos e metodológicos das atividades realizadas na educação do Ensino Superior. Em 1999, a UNESCO divulgou - em seu Relatório da Comissão Internacional sobre Educação para o Século XXI - a determinação de parâmetros de concepção da educação do novo milênio a partir de quatro pilares principais: "aprender a conhecer, aprender a fazer, aprender a conviver e aprender a ser" (DELORS, 2011).

Tais pensamentos exigem que a formação do profissional contemporâneo esteja pautada no desenvolvimento de uma educação integral do acadêmico. Há a necessidade de proporcionar ao indivíduo um conhecimento dinâmico do mundo, dos outros e de si mesmo, capacitando-o para o exercício profissional em tais tempos de mudanças dos paradigmas cognitivos.

Assim, durante sua formação, o aluno necessita receber subsídios que lhe atribuam capacidade cognitiva e habilidades para atuar, com competência, em um âmbito profissional cada dia mais complexo. Tal ponto de vista promove uma formação voltada à interdisciplinaridade, tendo como principais indicadores a articulação entre as áreas do conhecimento e a qualidade das relações interpessoais. Thiesen (2008), por exemplo, aponta que:

\begin{abstract}
A interdisciplinaridade será articuladora do processo de ensino e de aprendizagem na medida em que se produzir como atitude, como modo de pensar, como pressuposto na organização curricular, como fundamento para as opções metodológicas do ensinar, ou ainda como elemento orientador na formação dos profissionais da educação. (THIESEN, 2008 p.546).
\end{abstract}

Neste contexto, Flávio Motta (ROCHA, 2007) compreende o projeto como o arranjo de coisas e ideias dispostas de maneira interdisciplinar a fim de combater a fragmentação do conhecimento. Em complementação, o famoso arquiteto Paulo Mendes da Rocha (2007 p.19) afirma que, ao fazer um projeto, o indivíduo "deve ser capaz de invocar a memória sobre um saber, ainda que não tenha consciência de que sabe".

Logo, o profissional de arquitetura e urbanismo, uma vez que se insere no mercado de trabalho contemporâneo, precisa estar apto a se reinventar constantemente, afinal "o mundo do trabalho vive sua maior transformação desde a Revolução Industrial e busca um novo tipo de pessoa” (RUBIN, 2018). Metodologias industriais como o Fordismo trouxeram uma forma de pensamento mecânico e segmentado, onde as tarefas laborais passaram por um grande processo reducionista. No entanto, os novos desenvolvimentos tecnológicos do século XX estão permitindo o uso de um pensamento mais complexo.

Isso significa que o arquiteto em formação precisa desenvolver a capacidade de conectar melhor esse conhecimento fragmentado mencionado 
por Motta, a fim de desenvolver novas soluções para os problemas apresentados hoje. Ou seja, o indivíduo deve ser capaz de adequar o conhecimento adquirido em diferentes formas, uma vez que a constante transformação tecnológica exige adaptabilidade. Ademais, diversas teorias metodológicas vigentes conceituam o fazer arquitetura como um processo de resolução de uma problemática apresentada, onde:

\begin{abstract}
A arquitetura é geralmente concebida - projetada - e realizada construída - em resposta a um conjunto de condições existentes. Essas condições podem ser de natureza puramente funcional ou podem também refletir, em graus variados, a atmosfera social, política e econômica. De qualquer maneira, pressupõe-se que o conjunto de condições existentes - o problema - seja pouco satisfatório e que um novo conjunto de condições - uma solução se faça desejável. 0 ato de criar arquitetura, portanto, constitui um processo de resolução de problemas ou de projeto. (CHING, 2008).
\end{abstract}

Assim, entende-se que o projeto arquitetônico realizado é uma - única - dentre várias possíveis soluções a serem empregadas para atender às necessidades apresentadas. No entanto, com as grandes transformações tecnológicas e sociais que vêm ocorrendo nos últimos anos, há a necessidade do profissional de se adaptar constantemente a fim de buscar por respostas diferentes aos novos problemas que se apresentam no dia-a-dia do novo milênio. Como apontado por Lawson (2011), "os projetistas de hoje não podem mais ser treinados para seguir um conjunto de procedimentos, já que o ritmo das mudanças no mundo no qual têm de trabalhar logo os deixaria para trás".

Dentro desta questão, existe o considerável impacto das ferramentas computacionais sobre o processo de produção da arquitetura. As últimas décadas viram surgir um crescente interesse pelos processos de representação tridimensional. Mais ainda, este interesse vem acompanhado pela disseminação dos programas de desenho e reprodução por computador onde o espaço virtual ganha destaque (CONZALEZ, 2017).

No entanto, como apontado por Farrelly (2011), “a criação de desenhos em CAD e maquetes eletrônicas não deve ser considerada como um substituto para o uso de maquetes tradicionais, desenhos à mão e croqui". É necessário ter a consciência de que as ferramentas virtuais desempenham papéis específicos no processo de projeto e que não substituem as representações bidimensionais ou tradicionais. Logo, a representação do objeto passa a ter significativa importância no processo de projeto.

Assim, a expressão gráfica se faz essencial na produção do projeto arquitetônico uma vez que para projetar o sujeito deve ter o que Rêgo (2011) chama de capacidade visiográfica-tridimensional. Esta capacidade se relaciona à habilidade de compreender formas tridimensionais e representá-las graficamente. Seguindo o pensamento da autora, entende-se que a representação gráfica da linguagem visiográfica torna-se o principal processo dialógico entre o sujeito e o objeto em estudo para melhor compreensão e produção do espaço. E o desenvolvimento dessa capacidade estaria diretamente ligado à educação gráfica recebida pelo arquiteto, e que, quando 
potencializada, poderia repercutir diretamente no processo criativo projetual do indivíduo.

Portanto, tendo em vista os novos paradigmas cognitivos de aprendizagem e a necessidade de versatilidade do profissional de arquitetura e urbanismo do século XXI, como preparar os acadêmicos para esse novo contexto e, consequentemente, para o mercado de trabalho competitivo? Vêse a necessidade de estimular o profissional em formação desde a sala de aula, fomentando a criatividade e criando a habilidade de constantemente reimaginar o espaço construído, trazendo inovação à profissão em uma sociedade em constante transformação.

Assim, com o intuito de aprimorar nos alunos as noções de escala, estrutura e sentido do espaço, foi proposto um experimento de interdisciplinaridade com o $4^{\circ}$ período do Curso de Arquitetura e Urbanismo da FACIMED, em Cacoal/RO. O planejamento das disciplinas de DOMER II (Desenho e Outros Meios de Expressão e Representação) e História e Teoria da Arquitetura e Urbanismo II foi interligado a fim de ampliar e aprofundar a visão global do aluno de arquitetura e urbanismo. Por meio do estudo da forma e do volume, utilizaram-se técnicas de expressão e representação como métodos de investigação de projetos de arquitetura conceituados. Aqui, a maquete física passa a ser o objeto de estudo crítico e argumentativo na produção da arquitetura.

Deste modo, o presente trabalho tem por objetivo levantar uma discussão pedagógica-metodológica sobre $\mathrm{o}$ ensino da arquitetura $\mathrm{e}$ urbanismo e o uso de ferramentas tradicionais de representação do espaço. Através deste laboratório de pesquisa, a maquete física configura-se como ferramenta essencial na articulação da concepção projetual.

\section{ENTENDIMENTO DO ESPAÇO CONSTRUÍDO}

Estes novos modelos educacionais vêm sendo apresentados a fim de provocar uma ruptura epistemológica na formação do profissional de arquitetura e urbanismo contemporâneo. A educação superior passa a ter uma modalidade de formação que possibilita ao indivíduo o desenvolvimento de sua capacidade de gerar conhecimentos a partir de uma postura dialógica com a realidade. Uma vez que as transformações tecnológicas e sociais que vêm surgindo estão fazendo com que o mercado de trabalho esteja em constante mudança, o novo arquiteto e urbanista deve estar apto a uma rápida e, por vezes, profunda adaptação à realidade que o cerca.

A fim de lidar com estes paradigmas emergentes, novas metodologias de apropriação da informação e produção do conhecimento propõem o ensino da arquitetura em torno do exercício de cognição espacial. Este é um meio que objetiva o processo de formação integral do profissional através da junção do desenvolvimento de conhecimentos e competências. É preciso, então, entender o espaço e suas peculiaridades a fim de visualizá-lo de forma objetiva e, por fim, representá-lo graficamente. Nesta perspectiva: 
0 principal e fundamental problema diz respeito à possibilidade de desmontar cognitivamente o mecanismo, afinal simples, do desenho, e a seguir procurar compreender como aparece posto de todas as vezes que tem de ocorrer a diferentes tarefas. (MASSIRONI, 2010).

Isso mostra a necessidade de se trabalhar o léxico de elementos arquitetônicos a partir do processo de investigação, e perceber de que maneira esses elementos contribuíram com o corpus disciplinar da arquitetura. Faz-se mister a investigação de elementos componentes e articuladores de um todo maior, e não apenas dos objetos plásticos em seu conjunto total. Como dito em famosa citação pelo historiador de arquitetura Vincent Scully, "a arquitetura é um diálogo travado pelas gerações no decorrer do tempo". Porém, uma vez que a arquitetura lida com o espaço, materiais e partes que o compõem e definem, como fazer esse diálogo com a realidade sem usar palavras?

A utilização de sinais não verbais de comunicação faz parte da própria natureza da disciplina de arquitetura e urbanismo. Elementos como desenhos, croquis, diagramas e maquetes apresentam-se como instrumentos intrinsecamente elásticos e estimuladores no processo de comunicação da profissão. Como dito por Massironi (2010), "esta técnica essencial e primária, baseada nos processos de visão, encontra meios e matizes para se adaptar às mais variadas exigências".

Portanto, a manipulação do objeto arquitetônico com o intuito de desconstrução para entendimento das diferentes partes que o compõem, analisando-os em sua independência, auxilia na construção - aos poucos - da compreensão do conjunto através de uma técnica de representação da realidade. Elaborar um estudo de caso sobre uma obra referência é uma das formas mais simples e objetivas de adquirir vocabulário projetual e, como diz Ching (2008), "se nossa compreensão de uma linguagem de projeto é limitada, o espectro de soluções possíveis a um problema também será limitado". Sobre o assunto, é possível afirmar que:

\begin{abstract}
A percepção pode ser assimilada a um processo de 'descodificação' da realidade exterior ao observador; esta comporta uma atribuição de sentido e uma aquisição de significado que coexistencialmente tem a ver com a estruturação das imagens. A representação concreta, pelo contrário, pode ser vista como uma 'postura em código', isto é, um processo através do qual se escolhem, se constroem e se justapõem os sinais gráficos com a finalidade de atingir esse significado; ou seja, trata-se da formalização de uma mensagem visiva cuja descodificação esteja prevista dentro de um limite preciso. (MASSIRONI, 2010).
\end{abstract}

O desenvolvimento destas ferramentas de investigação possibilita o futuro profissional a aplicar essa habilidade adquirida nos projetos que porventura será responsável em sua carreira. Uma vez que o processo projetual arquitetônico apresenta hoje grande complexidade, o projetista passa a fazer uso de "diferentes tipos de pensamento que podem trabalhar paralelamente, ou não, dependendo do estágio da projetação, como também das especificidades e natureza do problema projetual"(RÊGG, 2011). Tendo em vista que a probabilidade do egresso de se deparar com temas projetuais 
nunca antes vistos - devido ao tempo relativamente reduzido da graduação -, é importante o incentivo da independência nessa busca de embasamento e investigação sobre o tema projetual.

\section{MAQUETE COMO INSTRUMENTO ARTICULADOR}

Hoje, o papel do professor de ensino superior se centra fundamentalmente na dinamização do grupo na busca da informação coletiva e individual. Ele assume funções de organização das atividades, de motivação e criação de um clima agradável de aprendizagem. Desempenhando a função de mediador, proporciona experiências para auto-aprendizagem e a construção do conhecimento.

Dentre as atividades em sala de aula, uma ferramenta usual em cursos de arquitetura e urbanismo é a utilização de estudos de caso, onde se faz a análise de obras. É possível fazer essa análise de projeto apenas através de observação. No entanto, quando se vai além e se reproduz uma "mini construção", ou seja, uma maquete, a compreensão desse mesmo projeto é muito mais aprofundada. Pois, para construir, se faz necessário entender como os ambientes se articulam, quais são as aberturas, quais são os acessos, entre outros elementos. Mais do que isso, ao materializar o objeto em estudo, o aluno (ou arquiteto) tem a possibilidade de interagir com esses elementos no ambiente físico. Como dito por Bruno Zevi (2009), a quarta dimensão - o tempo - qualifica e representa o objeto. Ao estudar um projeto de pontos de vista diferentes e sucessivos, "a quarta dimensão dá ao espaço a sua realidade integral".

No ambiente da graduação nem sempre há uma imediata compreensão por parte do aluno de uma planta baixa, pois a representação gráfica 2D não é universalmente acessível em um primeiro momento. Portanto, a elaboração de uma maquete pode ser de grande ajuda para o discente, especialmente aquele que ainda não tem essa visão. Sobre a necessidade do embasamento teórico, pode-se dizer que:

\footnotetext{
É possível estabelecer uma analogia com a maneira como precisamos conhecer e compreender o alfabeto antes que possamos formar palavras e desenvolver um vocabulário, como precisamos compreender as regras da gramática e sintaxe antes que possamos construir sentenças; precisamos entender os princípios de composição antes que possamos escrever ensaios, romances e coisas do gênero. Uma vez que esses elementos forem compreendidos, poderemos escrever com pujança ou com força, rogar pela paz ou incitar à revolta; comentar sobre o trivial ou falar com profundidade e relevância. De maneira semelhante, talvez seja apropriado sermos capazes de reconhecer os elementos básicos da forma e espaço e entendermos como podem ser manipulados e organizados no desenvolvimento de um conceito de projeto, antes de nos voltarmos para a questão mais vital do sentido na arquitetura. (CHING, 2008).
}

Pode-se somar o pressuposto acima com a ideia de que: 


\begin{abstract}
Uma vantagem importante de utilizar maquetes é que são uma fonte de informação potencialmente ricas, já que proporcionam três dimensões nas quais quer apresentar informações e a oportunidade de utilizar grandes quantidades de propriedades do mundo "real", por exemplo: tamanho, forma, cor e textura. Assim, como a linguagem da maquete é tão densa, a codificação de cada parte da informação pode ser mais compacta, do que se tem como resultado uma diminuição do tempo de decodificação na hora de assimilar para a realidade. (DUNN, 2010).
\end{abstract}

Entende-se, portanto, que é necessário o quanto antes na academia que o discente desenvolva uma base analítica a fim de criar seu próprio repertório projetual. Uma das formas mais vantajosas de fornecer essa capacidade de análise é através da utilização da maquete, pois, muito além de uma análise visual, para criar uma maquete - um protótipo da construção real - o aluno se vê estimulado a verdadeiramente apreender o objeto de estudo. $\mathrm{Na}$ medida em que precisa interpretar o projeto, com todos os seus pormenores, o sujeito filtra as características importantes, decompõe diferentes elementos do mesmo, a fim de representá-lo corretamente. Ressalta-se que para o bom desenvolvimento do protótipo, o aluno, além de juntar todas essas informações, deve organizá-las cronologicamente de maneira a reproduzi-las na ordem correta, pois se a maquete física é uma junção de camadas sobrepostas, se faz necessário estudar qual camada vem primeiro, qual deve segui-la na sequência e assim por diante.

Deste modo, tendo que fragmentar toda essa informação existente e necessária para a configuração do projeto como um todo, a assimilação da realidade se faz de maneira mais natural e intuitiva e, até pode-se dizer, mais rápida. Ela permite o conhecimento do espaço além da imaginação. Essa decodificação, responsável por transcender o ideal para o real, ou seja, do projeto para o protótipo, transforma na mesma medida a informação em conhecimento, enriquecendo sobremaneira o repertório arquitetônico do aluno.

Foi possível experimentar o discorrido acima em uma disciplina universitária, onde buscou-se a elaboração de maquetes físicas para apresentação de estudos de caso de obras residenciais consagradas da arquitetura. A experiência findou mostrando-se positiva afora as expectativas, pois trouxe conclusões além das esperadas, como será possível ver no relato de caso a seguir.

\title{
4. RELATO DE CASO
}

$\mathrm{O}$ século $\mathrm{XX}$ viu surgir diversos teóricos da arquitetura e urbanismo que dedicaram grande parte de seu tempo para analisar consagradas obras projetuais. Até os dias de hoje, este processo analítico configura-se como importante parte da cultura arquitetônica contemporânea. A fim de entender as potencialidades e consequências criadas por um projeto, o método analítico caracteriza-se como importante exercício processual cíclico de entendimento 
do objeto arquitetônico. Para Rocha-Peixoto et. al (2011), nesta análise do objeto:

Aquele que busca fazê-lo [o objeto] falar não é um simples decifrador de sinais, mas alguém que com ele trava um diálogo, instaurando uma abertura de compreender. É um humano ativo, em situação, que retira o objeto de sua inércia estabelecendo com ele vínculos de significação expressos em narrativas. 0 objeto por si só nada significa: são as narrativas que lhe conferem sentido. (ROCHA-PEIXOTO et al, 2011, p.23)

Assim, estes estudos de projetos - comumente referidos em cursos de arquitetura e urbanismo como estudos de caso - podem ser considerados referências projetuais importantes na produção do espaço construído ao viabilizar um processo reflexivo de análise. Eles configuram exemplos arquitetônicos correlatos em termos de função, tipologia, soluções plásticas ou sistemas estruturais, podendo ainda serem exploradas outras características.

O exercício do estudo de caso apresenta-se como mais um instrumento para a formação de um repertório enriquecido do arquiteto, além de ser referência de qualidade para os estudos teóricos e práticos no campo profissional da arquitetura e urbanismo. Como dito por Beltramin (2015), "o domínio do vocabulário na arquitetura é fator decisivo na qualidade e na riqueza da análise". A autora ainda afirma que "quanto maior e mais diversificado é o repertório arquitetônico, mais apurada e detalhada poderá ser a análise de determinado projeto ou obra construída".

Muitos são os autores que fazem analogia à arquitetura como um sistema gramatical complexo e específico. Assim como no aprendizado de uma língua, parte-se do pressuposto de que, ao se entender as regras gramaticais, o indivíduo pode se comunicar facilmente. Isso significa que o entendimento das diversas partes compositivas e de suas relações intrínsecas, individual e coletivamente, permitirão a compreensão do todo arquitetônico. Para tanto, é necessário adquirir vocabulário, chamado na disciplina de arquitetura e urbanismo de repertório de projeto. Bruno Zevi (2009) diz que para, verdadeiramente, ensinar o claro entendimento da arquitetura, faz-se necessária uma clareza de método. 0 autor ainda afirma que:

\footnotetext{
O leitor médio que tem acesso aos livros de estética e de crítica arquitetônica fica horrorizado com a imprecisão dos termos: 'verdade', 'movimento', 'força', 'vitalidade', 'sentido dos limites', 'harmonia', 'graça', 'repouso', 'escala', 'balance', 'proporção', 'luz e sombra', 'eurritmia', 'cheios e vazios', 'simetria', 'ritmo', 'massa', 'volume', 'ênfase', 'caráter', 'contraste', 'personalidade', 'analogia' são atributos de arquitetura que os diversos autores registram, muitas vezes sem especificar a que se referem. (ZEVI, 2009).
}

Este vocabulário - quando de uma natureza correta, precisa e aprofundada - é criado gradativamente através do contínuo estudo e análise de obras. Isso permite que o arquiteto possa desenvolver um compêndio mental de aspectos físicos, técnicos, conceituais, ideológicos e socioeconômicos que integram um projeto e, eventualmente, poderão a vir auxiliar no processo criativo. 
Com tais conceitos em mente e no intuito de desenvolver um experimento de interdisciplinaridade, alinharam-se as atividades das disciplinas de DOMER II (Desenho e Outros Meios de Expressão e Representação) e História e Teoria da Arquitetura e Urbanismo II do 4o período do curso de Arquitetura e Urbanismo da FACIMED, em Cacoal/RO. Na disciplina de História, o objetivo era desenvolver no aluno a compreensão da trajetória da arquitetura a partir da Revolução Industrial até os dias atuais. Ao colocar o acadêmico a par das principais correntes, discussões teóricas e protagonistas da arquitetura mundial, possibilita-se enfatizar o olhar crítico do arquiteto sobre a história da produção arquitetônica, fazendo com que esta sirva como uma contribuição ao processo de projeto.

Assim, em paralelo às atividades de natureza expositiva e dialogada, com apresentação e discussão do conteúdo teórico da disciplina, foi proposto aos alunos o desenvolvimento de estudos de caso de obras exploradas em sala de aula. Foram selecionados projetos arquitetônicos residenciais do século XX, historicamente relevantes e consagrados como referências projetuais. Os acadêmicos desenvolveram estudos de clássicos conhecidos da profissão, como a Residência Rietveld Schröder na Holanda (1925) por Gerrit Rietveld; a Villa Savoye na França (1929) por Le Corbusier; a Casa da Cascata nos EUA (1939) por Frank Lloyd Wright; a Residência Eames em Los Angeles, EUA (1949) por Charles e Ray Eames; dentre outras.

Existem diversas metodologias que abordam o desenvolvimento do estudo analítico de obras arquitetônicas. Para o presente relato de caso, foi selecionada a abordagem de Francis Ching (2008), relatada em seu livro Arquitetura: Forma, Espaço e Ordem. Para o autor, a análise do objeto arquitetônico deve ser feita a partir de conceitos básicos de estruturação e definição - sistema, ordem, forma e espaço. Ou seja, os elementos arquitetônicos constituem um sistema. Por conseguinte, os diferentes sistemas se relacionam para formar um todo. Esse todo pode ser percebido a partir de diferentes formas, criando as ordens de organização e percepção do objeto. E, através da vivência de todas essas ordens, tem-se o objeto arquitetônico em sua completude, através de uma estrutura unificada e coerente (BELTRAMIN, 2015; CHING, 2008).

Assim, foram extrapoladas algumas diretrizes metodológicas de desenvolvimento de estudos de caso formais, sendo apresentadas aos alunos diretrizes, organizadas em quatro fases gerais. A primeira fase do estudo de caso, Contextualização do Projeto, voltou-se ao levantamento de informações gerais sobre a obra. Foram elencados dados sobre identificação e contextualização geral do projeto, assim como características físicas da obra. Foi também realizado um levantamento documental arquitetônico a fim de se ter plantas, cortes e elevações, além de levantamento fotográfico.

A segunda fase, Caracterização Física do Projeto, lidou com a identificação espacial do objeto em estudo. É importante nessa etapa tirar proveito dos elementos primários de composição (ponto, reta, plano e volume), o modo como são percebidos, suas características (delimitação, dimensionamento, relacionamento entre si, etc.) e as ideias que expressam 
dentro da composição. A partir daí passa-se a olhar para a forma enquanto maneira de dispor e coordenar os elementos e partes de uma composição a fim de produzir uma imagem coerente (CHING, 2008).

Pode-se abordar questões de propriedades visuais - como formato, tamanho, cor e textura -, assim como propriedades relacionais - como orientação, posição e inércia visual -, que determinam o padrão e a composição dos elementos formais. No entanto, faz-se mister olhar não somente para as partes, mas também para o todo. Dentro da composição da obra, percebem-se padrões e intenções de modificação do espaço. 0 resultado pode ser uma composição com formas regulares ou irregulares; uma ou mais dimensões podem ser manipuladas; ou até é possível haver adição ou subtração de planos e/ou volumes para compor ou decompor a forma do conjunto.

A terceira fase, Análise Crítica do Projeto, foi dedicada à avaliação da obra em termos espaciais. Esta etapa configurou-se como um processo de pesquisa analítica do projeto. Uma das ferramentas disponíveis é a pesquisa realizada pelo método gráfico interpretativo, ou seja, por desenhos diagramáticos. Estes desenhos são mais que meramente artísticos, devendo apresentar as articulações entre diferentes elementos. Desta forma, é possível verificar o papel dos condicionantes sobre a solução arquitetônica adotada. Elementos como organização, circulação, proporção e escala são estudados. A análise dos princípios ordenadores da forma e do espaço na arquitetura - eixo, simetria, hierarquia, ritmo, referência, transformação - tem por objetivo descrever os processos compositivos da arquitetura e as maneiras pelas quais os sistemas arquitetônicos são combinados e organizados.

Por fim, a quarta e última fase faz necessário chegar a uma conclusão argumentada a partir da análise do estudo de caso. Apresenta-se aqui a avaliação do significado e importância da obra, em relação ao tema em que se insere - o que significa também levantar problemas, dúvidas e críticas.

No entanto, como apontado por Zevi (2009), o método de representação dos edifícios estudados em disciplinas de histórias da arte e da arquitetura serve-se de plantas, elevações, cortes ou seções e fotografias como meios de expressão. Ainda segundo o autor:

\footnotetext{
Isoladamente e no seu conjunto, esses instrumentos são incapazes de representar completamente o espaço arquitetônico, mas é útil aprofundar o assunto porque - se até agora não temos à nossa disposição melhores meios representativos - a nossa missão é estudar a técnica de que dispomos e torná-la mais eficiente.
}

Logo, em paralelo à disciplina de História, na disciplina de DOMER, foi desenvolvido uma espécie de laboratório de pesquisa, onde os alunos passaram a ser encarregados do desenvolvimento do conhecimento. A disciplina propôs o estudo da questão da forma ao enfatizar a importância de aspectos plásticos e perceptivos do processo de decomposição do objeto arquitetônico em análise. Para tanto, foi solicitado aos alunos a elaboração de maquetes físicas como instrumento de expressão e representação gráfica para o exercício de análise e pesquisa destes objetos. Exigiu-se a utilização de 
apenas uma cor, a branca, para se retirar a materialização da análise - já estudada na teoria - e focar na forma compositiva para desenvolvimento das ferramentas cognitivas de projeto. Neste contexto:

As maquetes convencionais permitem ao arquiteto explorar uma ideia tridimensionalmente; elas expressam uma ideia de arquitetura de maneira acessível, mostrando imediatamente detalhes da escala, da forma e dos materiais, e podem ser criadas como protótipos de um elemento em tamanho real (como uma porta ou uma janela), na escala de um cômodo ou mesmo na escala de uma cidade (uma maquete de urbanismo). As maquetes permitem que uma ideia seja estudada em mais detalhes, pois certos elementos do projeto suas escalas às vezes não são compreendidos até que sejam vistos no contexto de uma forma modelada. (FARRELLY, 2011).

Assim, com o objetivo de reforçar a ideia da interdisciplinaridade, as mesmas quatro fases da disciplina de História foram utilizadas em DOMER. No entanto, o foco de cada uma foi redirecionado para atender às necessidades específicas da disciplina, na medida em que a primeira visava uma análise mais teórica e funcional enquanto que a segunda buscava somar à essa análise aspectos plásticos e estéticos através da maquete. Logo, a primeira fase de Contextualização do Projeto teve o intuito de utilizar as informações coletadas em paralelo na outra disciplina a fim de embasar as escolhas práticas de manufatura da maquete. Foram tomadas decisões pertinentes à escolha de materiais de confecção assim como a definição da escala de representação.

$\mathrm{Na}$ fase de Caracterização Física do Projeto, foram desenvolvidos estudos sequenciais de modelagem física do objeto. Ao diminuir a escala do projeto arquitetônico, força-se o aluno a pensar nos elementos essenciais que representam a identidade vital do objeto em estudo. Afinal, "refletir sobre a importância do modelo reduzido é pensar na importância de manejar a história da humanidade" (PINA et al., 2011). Logo, lida-se aqui com a decomposição física do objeto, onde o aluno precisa pensar nas diferentes partes que compõem a forma e como elas se relacionam.

Configura-se uma etapa de preparação e reconhecimento das informações teóricas compiladas na outra disciplina. Aqui, pode-se passar por um segundo momento de escolhas de materiais de confecção, uma vez que por mais que a cor final escolhida seja a branca, a representação das texturas influenciará o entendimento final do produto. Desta forma, a maquete funciona como um croqui, na medida em que permite a investigação e o estudo de possibilidades. Como dito por Dunn (2010):

Cada maquete tem um propósito e um usuário específicos, e não é possível reduzir todas as possíveis ideias de desenho em uma única. Em primeira instância pode funcionar simplesmente como uma ferramenta de desenho, e assim permitir ao criador explorar uma ideia concreta ou analisar evoluções sucessivas. Em um segundo momento, pode utilizar-se para apresentar ou demonstrar ideias de desenho a uma audiência determinada para que os demais compartilhem a sua visão de projeto. (DUNN, 2010) 
Paulo Mendes da Rocha, em seu livro Maquete de Papel, corrobora com esta ideia ao dizer que este produto:

É a maquete como instrumento de desenho. Em vez de você desenhar, você faz maquete. Não tem nada a ver com as maquetes profissionais, do maquetista que tem a função de mostrar a ideia já pronta. Esse é o objeto que pode ser encomendado para ser exibido, e tem seu valor. A maquete aqui é um instrumento que faz parte do processo de trabalho; são pequenos modelos simples. Não é para ninguém ver. (ROCHA, 2007)

A fase de Análise Crítica do Projeto passa então a trabalhar com a composição dessas ideias elencadas na fase anterior. Agora, a medida que o aluno constrói seu objeto final (vide Figura 1), ele também consolida as avaliações a fim de chegar às suas conclusões acerca da obra. Este processo permite a apreensão de novas informações que irão expandir o repertório projetual do discente. Pois, quando uma obra é reconhecidamente de qualidade, cabe ao indivíduo "dar um passo atrás e perguntar: são, mas por que razão o arquiteto fez isso? Então você descobre muitas coisas interessantes" (ROCHA, 2007).

Figura 1: Maquetes confeccionadas na disciplina de DOMER II: à esquerda, representação da Villa Savoye em Poissy, França (1929) por Le Corbusier; à direita, representação da Residência Eames em Los Angeles, EUA (1949) por Charles e Ray Eames.
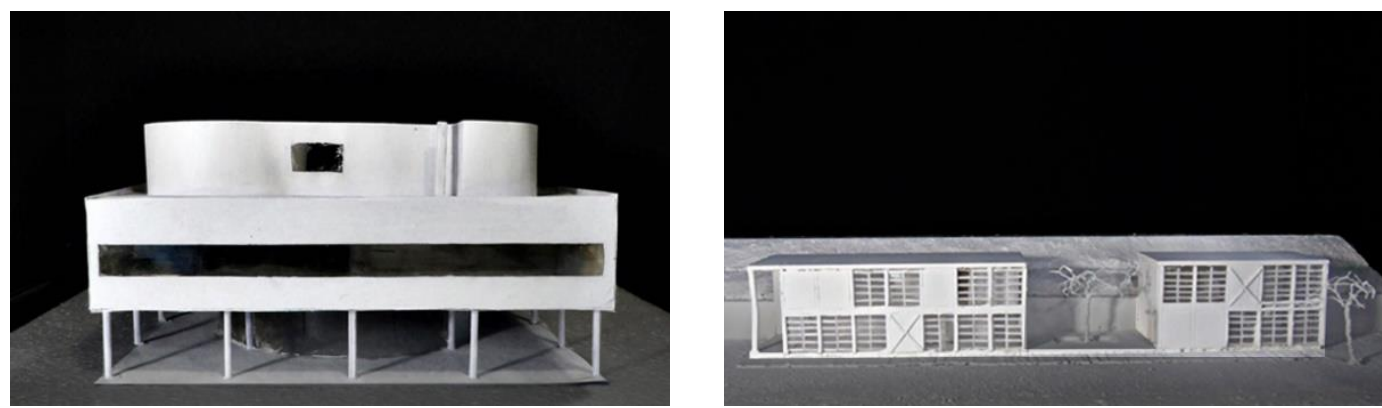

Fonte: Acervo das autoras (2017).

Quando a representação é menor que a escala real de 1/1, é preciso decidir quais elementos representar e como representá-los. Qualquer codificação exige um processo de escolhas. Partes deverão ser descartadas, o que faz com que permaneça o essencial para o entendimento e reconhecimento completo da obra. Um dos objetivos desta atividade é proporcionar ao aluno uma experiência de curadoria da informação, uma vez que, além da confecção das maquetes, eles deveriam criar imagens do produto final e desenvolver uma exposição para os demais alunos da faculdade de Arquitetura e Urbanismo da FACIMED (Figura 2).

Figura 2: Imagens ilustrativas das atividades da disciplina de DOMER II. 

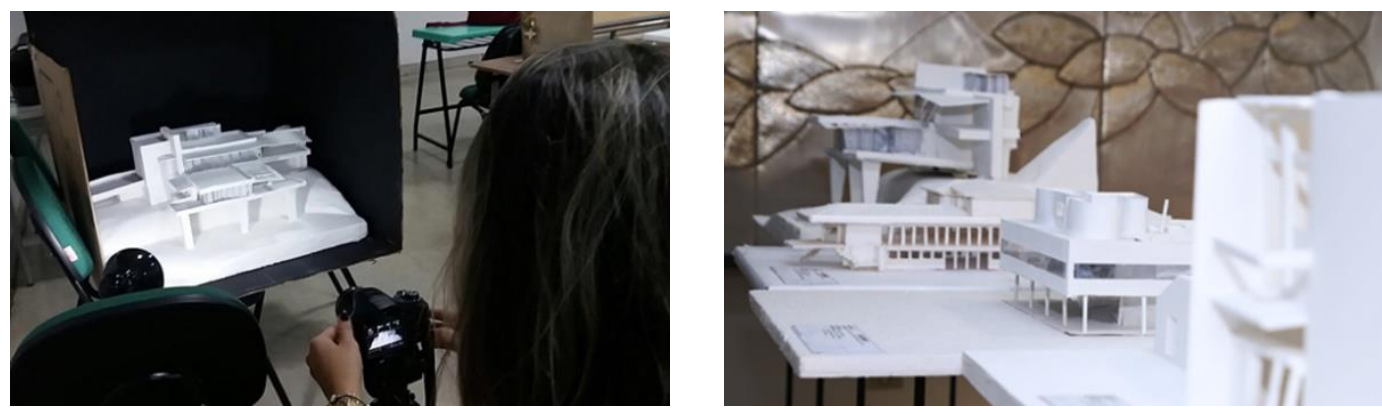

Fonte: Acervo das autoras (2017).

Partiu-se da ideia de que, ao longo desse laboratório experimental, os alunos foram capazes de analisar, comparar e discutir uma obra a fim de transformar a informação em conhecimento, expressando sua opinião sobre o tema discutido. Como apresentado por Pina et al. (2011), "a maquete serve para testar ideias globais e interagir com as demais linguagens gráficas [...]. A maquete é o elemento mais direto de estudo de detalhes específicos, sua execução e a comunicação de ideias".

Ou seja, a própria confecção da maquete fornece os meios para esse processo de aprendizagem. Portanto, a quantificação do desenvolvimento dos alunos se deu por Avaliação Continuada. A nota final correspondeu à média ponderada da nota de assessoramentos ao longo da disciplina (25\%), da nota da primeira apresentação ao final da segunda fase (25\%) e da nota da entrega final (50\%), todas variando de 0 a 10 . 0 acompanhamento deste desenvolvimento deu-se por assessoria em grupo e individuais, onde o aluno pode perceber ao longo da disciplina o seu desempenho. Isso significa que ele vai paulatinamente construindo sua própria nota à medida que constrói seu pensamento investigativo.

\section{CONSIDERAÇÕES FINAIS}

O desenvolvimento de capacidades cognitivas e habilidades complexas proposto por esse estudo, liga-se às ideias de interdisciplinaridade que propiciam além da articulação entre as áreas do conhecimento, a melhoria da qualidade das relações interpessoais. Isso é melhor percebido no momento de fechamento das disciplinas que se deu de modo único, através de seminário, onde cada grupo dispôs as suas conclusões acerca do desenvolvimento do estudo de caso e da maquete.

Algo enriquecedor foi o espaço de discussões e debates criado a fim de proporcionar a troca de conhecimento entre os alunos, que se apresentam como pesquisadores de seu próprio objeto. Ao expor o seu processo de investigação, oportuniza-se outros pontos de vista. Todos os alunos passaram pelo mesmo processo metodológico, no entanto, uma vez que cada indivíduo é único - e possui seu próprio repertório - suas pontuações, observações e conclusões serão diversas.

Além disso, esse indivíduo pode enxergar um paralelo entre o trabalho apresentado por outrem e seu próprio trabalho, multiplicando assim o 
conhecimento. Ou seja, além das conclusões individuais proporcionadas por cada objeto de estudo, a permuta criada no debate potencializa o surgimento de novas ideias. Tal dinâmica incentiva a retroalimentação do processo de pesquisa, indagação e investigação a partir da formação de um conhecimento através de um processo cíclico.

0 exercício permitiu aos alunos chegarem a uma decomposição máxima das obras estudadas, através da representação com o menor número de linhas possíveis do elemento que eles construíram. Pois, como exposto a seguir:

Não se trata de fazer pequenas dobraduras e com isso encontrar a solução para o problema [...]. A maquete, muito simples, está realizando uma coisa que você quer ver. 0 diâmetro certo, a altura certa, a escala humana. Você consegue ser esse personagem, ajoelha no chão para ver dentro da maquete [...] até ficar imerso naquele espaço. (ROCHA, 2007 P.58)

Dá-se, assim, a possibilidade de materializar e de interagir com o elemento no ambiente físico. Como já dito anteriormente, é a utilização da quarta dimensão de Bruno Zevi, ao se buscar a manipulação do objeto. Com a experiência, entende-se que o saber está além dos livros, pois, embora essenciais, nem sempre são compreensíveis. A utilização da maquete na análise da forma passa a ser então uma língua universal, acessível a todos.

A reprodução dessas obras icônicas fez os alunos perceberem elementos existentes nas construções, além de forçá-los a se empenhar a ultrapassar as dificuldades que se apresentam ao longo do caminho projetual. Ademais, expor esse trabalho de pesquisa ao resto da comunidade acadêmica da faculdade auxiliou em um processo de empoderamento dos alunos, que se sentiram muito mais confiantes após a visualização concreta dos resultados alcançados.

Portanto, em um mundo de constantes transformações, espera-se do profissional do século XXI a contribuição para o saber científico da arquitetura, estando ele aberto à crítica argumentativa e fundamentada. Fazendo-se uso dos saberes já existentes de técnica e estética, é preciso que esse profissional saiba "escolher na escala dos valores contidos entre dois valores extremos, a forma plástica apropriada a cada pormenor em função da unidade última da obra idealizada" (COSTA, 1995).

\section{REFERÊNCIAS BIBLIOGRÁFICAS}

BELTRAMIN, R. M. G. Caracterização e sistematização de quatro modelos de análise gráfica: Clark, Pause, Ching, Baker e Unwin. Dissertação (mestrado) - Universidade Estadual de Campinas, Faculdade de Engenharia Civil, Arquitetura e Urbanismo. Campinas, SP: [s.n.], 2015. 168p.

COSTA, Lúcio. Considerações sobre arte contemporânea (1940). In: Lúcio Costa, Registro de uma vivência. São Paulo: Empresa das Artes, 1995. 608p.il. 
CHING, Francis D. K. Arquitetura - forma, espaço e ordem. Editora: Martins Fontes, 2008.

DELORS, Jacques. Educação um tesouro a descobrir. São Paulo: Cortez, 2011. 288p.

DUNN, Nick. Architectural Modelmaking. Barcelona: Blume, 2010.

FARRELLY, Lorraine. Técnicas de representação. Porto Alegre: Bookman, 2011. 176p.

GOLDBERGER, Paul. A relevância da arquitetura. (trad. Roberto Grey). São Paulo: BEI Comunicações, 2011.

LAWSON, Bryan. Como arquitetos e designers pensam. Editora: Oficina de Textos, 2011. $296 \mathrm{p}$.

MASSIRONI, Manfredo. Ver pelo desenho. Lisboa: Edições 70, 2010. 208p.

PINA, Sílvia A. M. G.; BORGES FILHO, Francisco; MARANGONI, Renata F. Maquetes e modelos como estímulo à criatividade no projeto arquitetônico. In: KOWALTOWSKI, Doris. O Processo de Projeto Em Arquitetura da Teoria À Tecnologia. São Paulo: Oficina de Textos, 2011.

RÊGO, Rejane de Moraes. Educação gráfica e projetação arquitetônica: as relações a capacidade visiográfica-tridimensional e a utilização da modelagem geométrica 3D. São Paulo: Blucher Acadêmico, 2011.

ROCHA, Paulo Mendes da. Maquetes de papel. Curitiba: Cosac Naify, 2007.

ROCHA-PEIXOTO, Gustavo; BRONSTEIN, Laís; OLIVEIRA, Beatriz Santos de; LASSANCE, Guilherme. Às coisas mesmas: conversas com o objeto. In: ROCHA-PEIXOTO, Gustavo (Org.). Leituras em teoria da Arquitetura, 3: objetos. Rio de Janeiro: Rio Book's, 2011. 246p.

RUBIN, Débora. 0 profissional que o mercado quer. Revista IstoÉ.

Atualizado em: 21/01/2016. Disponível em:

<https://istoe.com.br/196912_O+PROFISSIONAL+QUE+O+MERCADO+QUER />. Acesso em: 24/08/2018.

THIESEN, Juares da Silva. A interdisciplinaridade como um movimento articulador no processo ensino-aprendizagem. Revista Brasileira de Educação, 2008. Disponível em:

<http://www.redalyc.org/articulo.oa?id=27503910>. Acesso em:

24/08/2018.

ZEVI, Bruno. Saber ver a arquitetura. 6a. ed. São Paulo: Editora WMF Martins Fontes, 2009. 